\title{
Mitochondrial coupling factor 6 as a potent endogenous vasoconstrictor
}

\author{
Tomohiro Osanai, ${ }^{1}$ Makoto Tanaka, ${ }^{1}$ Takaatsu Kamada, ${ }^{1}$ Takao Nakano, ${ }^{1}$ \\ Koki Takahashi, ${ }^{1}$ Satoko Okada, ${ }^{1}$ Kenichi Sirato, ${ }^{1}$ Koji Magota, ${ }^{2}$ \\ Shiho Kodama, ${ }^{2}$ and Ken Okumura ${ }^{1}$
}

${ }^{1}$ The Second Department of Internal Medicine, Hirosaki University School of Medicine, Hirosaki, Japan
${ }^{2}$ Pharmaceutical Research Laboratories, Suntory Biomedical Research Limited, Osaka, Japan

Address correspondence to: Tomohiro Osanai, The Second Department of Internal Medicine,

Hirosaki University School of Medicine, 5 Zaifu-cho, Hirosaki 036-8562, Japan.

Phone: 81-172-39-5057; Fax: 81-172-35-9190; E-mail: osanait@cc.hirosaki-u.ac.jp.

Received for publication August 16, 2000, and accepted in revised form July 27, 2001.

We demonstrated recently that coupling factor 6 , an essential component of the energy-transducing stalk of mitochondrial ATP synthase, suppresses the synthesis of prostacyclin in vascular endothelial cells. Here, we tested the hypothesis that coupling factor 6 is present on the cell surface and is involved in the regulation of systemic circulation. This peptide is present on the surface of CRL-2222 vascular endothelial cells and is released by these cells into the medium. In vivo, the peptide circulates in the vascular system of the rat, and its gene expression and plasma concentration are higher in spontaneously hypertensive rats (SHRs) than in normotensive controls. Elevation of blood pressure with norepinephrine did not affect the plasma concentration of coupling factor 6 . Intravenous injection of recombinant peptide increased blood pressure, apparently by suppressing prostacyclin synthesis, whereas a specific Ab to coupling factor 6 decreased systemic blood pressure concomitantly with an increase in plasma prostacyclin. Interestingly, the antibody's hypotensive effect could be abolished by treating with the cyclooxygenase inhibitor indomethacin. These findings indicate that mitochondrial coupling factor 6 functions as a potent endogenous vasoconstrictor in the fashion of a circulating hormone and may suggest a new mechanism for hypertension.

J. Clin. Invest. 108:1023-1030 (2001). DOI:10.1172/JCI200111076.

\section{Introduction}

Mitochondrial ATP synthase consists of three domains, namely the extrinsic and intrinsic membrane domains ( $F_{1}$ and $F_{0}$, respectively) joined by a stalk $(1,2)$. Four subunits of the stalk have been designated coupling factor 6 , oligomycin sensitivity-conferring protein, and subunits $b$ and $d(3-5)$. Coupling factor 6 was reported to be essential for energy transduction (6). We recently identified a novel function for coupling factor 6 while investigating the suppression of prostacyclin in spontaneously hypertensive rats (SHRs). Levels of circulating prostacyclin in SHRs were decreased compared with those in normotensive control Wistar Kyoto rats (WKYs), despite the fact that, as measured in isolated aortic strips, prostacyclin generation was elevated in SHRs $(7,8)$. We postulated that some endogenous prostacyclin synthesis inhibitor might be acting in SHRs and showed that mitochondrial coupling factor 6 is an endogenous inhibitor of prostacyclin synthesis in human vascular endothelial cells (9). Consistent with this hypothesis, both basal and bradykinininduced syntheses of prostacyclin were suppressed by human recombinant coupling factor 6 . Noting that mobilization of the prostacyclin precursor arachidonic acid (AA) was suppressed by coupling factor 6 and that a specific inhibitor of cytosolic phospholipase $A_{2}$
$\left(\mathrm{cPLA}_{2}\right)$ showed no additional effect on AA mobilization, we suggested that coupling factor 6 inhibits $\mathrm{CPLA}_{2}$ activity in vascular endothelial cells.

In vivo, prostacyclin $(10,11)$ inhibits salt-sensitive hypertension, as well as susceptibility to thrombosis, pain perception, and inflammatory responses. Various stimuli for prostacyclin synthesis, including vasoactive substances (12-14), growth factors $(15,16)$, and prostacyclin-stimulating factor (17) can induce these responses, which can be blocked either by treating with inhibitors of prostacyclin synthesis or by clearing the compound from the circulation.

Mitochondrial coupling factor 6 may well be the only endogenous, physiologically relevant inhibitor of prostacyclin generation that affects vascular function. Other candidate regulators include the prostaglandin (PG) transporter (18) and the $\mathrm{PLA}_{2}$ inhibitory protein lipomodulin (also known as macrocortin) (19-21). However, the PG transporter specifically mediates the vascular clearance of classical PGs other than prostacyclin during passage through the pulmonary circulation, and lipomodulin fails to counteract the inflammatory effect of prostacyclin in a physiological condition. Because $\alpha$ and $\beta$ subunits of ATP synthase have been identified on the cell surface of the vascular endothelial cells (where they function as a receptor for angiostatin) (22-29), we 
wished to test the possibility that mitochondrial coupling factor 6 is likewise expressed on these cells, whence it might be shed into the extracellular space. In the present study, we synthesized the peptide using a cleavable fusion protein strategy, established a specific radioimmunoassay (RIA) system, and examined the role of this peptide in the regulation of systemic blood pressure.

\section{Methods}

Animals. Male SHRs and WKYs at the ages of $4(n=5$, respectively) and 16 weeks ( $n=24$, respectively) were purchased from Charles River (Kanagawa, Japan), and maintained with standard rat chow and free access to water. Arterial blood was sampled from abdominal aorta into chilled tubes containing EDTA $2 \mathrm{Na}(1 \mathrm{mg} / \mathrm{ml})$. The plasma samples were separated by centrifugation at $4^{\circ} \mathrm{C}$ and stored at $-80^{\circ} \mathrm{C}$ until use.

Cell culture. Rat vascular endothelial cells (CRL-2222) were cultured in Earle's minimum essential medium containing $10 \% \mathrm{FBS}$ at $37^{\circ} \mathrm{C}$ under $5 \% \mathrm{CO}_{2}$. For analyses of coupling factor 6 accumulation in conditioned medium, confluent CRL-2222 cells were grown in 100-mm Petri dishes in serum-free Earle's minimum essential medium.

Materials. CRL-2222 cells were purchased from American Type Culture Collection (Rockville, Maryland, USA). Restriction enzymes, T4 DNA ligase, and Taq polymerase were from Takara-shuzo (Kyoto, Japan). Enterokinase was obtained from Stratagene (La Jolla, California, USA). Bradykinin and all other reagents were of the finest grade available from Sigma Chemical Co. (St. Louis, Missouri, USA). Sep-Pak C18 cartridge was purchased from Waters Chromatography Co. (Milford, Massachusetts, USA). Silica minicolumn (BOND ELUT) was from Varian Inc. (Harbor City, California, USA). Anti-rabbit IgG goat serum was from Japan Antibody Research Institute (Gunma, Japan). Nonspecific anti-rabbit IgG was from Jackson ImmunoResearch Laboratories Inc. (West Grove, Pennsylvania, USA). ImmunoPure Fab preparation kit was purchased from Pierce Chemical Co. (Rockford, Illinois, USA). Toxicolor Test was from Seikagaku Kogyo Ltd. (Tokyo, Japan). A tritiated 6-keto-PGF $1 \alpha$ tracer was purchased from New England Nuclear (Boston, Massachusetts, USA). The 6-keto-PGF ${ }_{1 \alpha} \mathrm{Ab}$ and standard were provided by Ono Pharmaceutical Co. (Osaka, Japan). All other reagents were of the highest grade available from Sigma Chemical Co.

Synthesis of recombinant coupling factor 6. Mature rat coupling factor 6 was obtained from Escherichia coli using a cleavable fusion protein strategy (30). A cDNA fragment encoding mature rat coupling factor 6 was amplified by PCR using CDNA derived from rat liver as a template and the oligonucleotides rCF6-01 5'-GAATTCGACGATGACGATAAGAATAA GGAACTTGATCCTGTACAG- ${ }^{\prime}$ and rCF6$025^{\prime}$-GTCGACTCAGGAC TGGGGTTTGTCGAG- $3^{\prime}$ with the Sall site. With rCF6E 5 -AGCACGCGT TCACATGACTGTCTCCCACT- $3^{\prime}$ and rCF6-02, the EcoRI site and the sequence encoding the enterokinase recognition site (DDDDK) were introduced in front of the mature rat coupling factor 6 . The $0.3-\mathrm{kb}$ EcoRI-SalI fragment cod- ing the DDDDK sequence and mature rat coupling factor 6 were inserted into the E. coli expression vector pG139S to generate pG139SrCF6EK. E. coli JM109 cells transformed with pG139SrCF6EK were cultured at $37^{\circ} \mathrm{C}$ in SB medium $(0.5 \%$ glycerol, $2.4 \%$ yeast extract, $1.2 \%$ tryptone, and $100 \mathrm{mM}$ potassium phosphate buffer at $\mathrm{pH} 7.5$ ) containing $10 \mu \mathrm{g} / \mathrm{ml}$ tetracycline. Cells were harvested by centrifugation, resuspended in solution $\mathrm{A}$ (20 mM Tris-HCl at $\mathrm{pH} 7.0,1 \mathrm{mM}$ EDTA, and $0.1 \%$ Triton X-100), and disrupted by sonication. The lysate was centrifuged and the pellet containing fusion protein was washed three times with solution A. Fusion protein was dissolved in $10 \mathrm{M}$ urea solution and diluted to $3.5 \mathrm{M}$ urea solution $(20 \mathrm{mM}$ Tris- $\mathrm{HCl}$ at $\mathrm{pH} 8.0,50 \mathrm{mM} \mathrm{NaCl}$, and $2 \mathrm{mM} \mathrm{CaCl}_{2}$ ). Enterokinase was added to the solution at an enzyme-substrate ratio of 1:1,200 (wt/wt), which was then incubated for 16 hours at $22^{\circ} \mathrm{C}$. Cleaved mature rat coupling factor 6 was solubilized in $0.1 \%$ trifluoroacetic acid (TFA) and purified by HPLC using YMC A-302 $(4.6 \times 150 \mathrm{~mm})$. Elution was carried out with linear gradient of $25.5 \%$ to $47.2 \%$ acetonitrile in a $0.1 \%$ TFA at flow rate of $1 \mathrm{ml} /$ minute for 54 minutes. Finally, the amino acid sequence and molecular mass of this peptide were checked by automated gas-phase peptide sequencer and mass spectrometry.

Endotoxin contamination was checked as follows: Recombinant coupling factor 6 was added to an aliquot of Toxicolor Test (a lyophilized mixture of amebocyte lysate from Trachypleus tridentatus and a chromogenic substrate, Boc-Leu-Gly-Arg-pNA) dissolved in Tris- $\mathrm{HCl}$ buffer, $\mathrm{pH}$ 8.0, and the mixture was incubated at $37^{\circ} \mathrm{C}$ for 30 minutes. Absorbance was measured at $545 \mathrm{~nm}$ after diazotization. The endotoxin concentration in the final preparation of recombinant coupling factor 6 was less than $1 \mathrm{pg} / \mathrm{ml}$.

Synthesis of $A b$ for rat coupling factor 6 . Synthetic coupling factor 6 fragment (rat Cys-58-76 amino acid) solution was emulsified with an equal volume of CFA and injected subcutaneously into New Zealand white rabbits at multiple sites in the interscapulovertebral region. The Fab fraction of anti-coupling factor $6 \mathrm{Ab}$ was prepared using ImmunoPure Fab Preparation Kit. Briefly, the coupling factor $6 \mathrm{Ab}$ was incubated with papain for 5 hours at $37^{\circ} \mathrm{C}$. The solubilized $\mathrm{Fab}$ and $\mathrm{Fc}$ fragments and undigested IgG were applied to the protein A column and washed with ImmunoPure binding buffer. The eluate was collected and dialyzed against PBS, pH 7.4, overnight. The concentration of endotoxin in anti-coupling factor $6 \mathrm{Ab}$ was less than $1 \mathrm{pg} / \mathrm{ml}$. Procedures for RIA of coupling factor 6 . The incubation buffer for RIA was $0.05 \mathrm{M}$ sodium phosphate buffer ( $\mathrm{pH}$ 7.4) containing $0.5 \% \mathrm{BSA}, 0.08 \mathrm{M} \mathrm{NaCl}, 0.025 \mathrm{M}$ EDTA $2 \mathrm{Na}$, and $0.05 \% \mathrm{NaN}_{3}$. All assay procedures were performed at $4^{\circ} \mathrm{C}$. The standard recombinant coupling factor 6 or the unknown sample $(100 \mu \mathrm{l})$ was incubated with anti-coupling factor 6 antiserum diluent $(100 \mu \mathrm{l})$ for 12 hours, then the tracer solution $(18,000-20,000$ cpm in $100 \mu \mathrm{l}$ ) was added. After incubation for 24 hours, anti-rabbit IgG goat serum diluent containing 
$10 \%$ polyethylene glycol $6,000(1,000 \mu \mathrm{l})$ and rabbit IgG at $200 \mu \mathrm{g} / \mathrm{ml}(100 \mu \mathrm{l})$ was added. After standing for 1 hour, the tubes were centrifuged at 2,000 $\mathrm{g}$ for $30 \mathrm{~min}$ utes at $4^{\circ} \mathrm{C}$, and radioactivity of the precipitate was measured with a gamma counter. The antiserum to coupling factor 6 detected the peptide with high affinity at a final dilution of 1:2,500. Half-maximum inhibition of radioiodinated ligand binding by rat recombinant coupling factor 6 was observed at $300 \mathrm{pg} /$ tube. An appropriate amount of cold recombinant coupling factor 6 added to the RIA sample was precisely determined by the present RIA. Recovery rate was more than $90 \%$ when the plasma sample was treated with a Sep-Pak $\mathrm{C}-18$ cartridge. The intra- and interassay coefficients of variance were $8 \%$ and $10.2 \%$, respectively.

Preparation of samples for RIA of coupling factor 6. Sep-Pak C18 cartridges were pre-equilibrated with saline and loaded either with plasma $(0.8 \mathrm{ml})$ acidified with $200 \mu \mathrm{l}$ of $\mathrm{HCl}$ or with culture medium. After washing three times with $5 \mathrm{ml}$ of water containing TFA, the absorbed materials were eluted with $2 \mathrm{ml}$ of $60 \%$ acetonitrile containing $0.1 \%$ TFA, collected, and lyophilized. The residual materials were dissolved in RIA buffer and the clear solution was submitted to RIA.

Characterization of immunoreactive substances in the plas$m a$. The immunoreactive substances present in the rat plasma were characterized by HPLC. The samples, treated with a Sep-Pak C18 cartridge, were applied on reverse-phase HPLC using an Inertsil ODS-2 C18 column $(4.6 \times 250 \mathrm{~mm}$; GL Science Inc. Tokyo, Japan $)$ and an acetonitrile $/ 0.1 \%$ TFA elusion at $20 \%$ acetonitrile over the first 5 minutes, followed by linear gradient of acetonitrile ranging from $20 \%$ to $60 \%$ over 30 minutes at a flow rate of $1 \mathrm{ml} /$ minute. The amino acid sequence of the immunoreactive fraction was examined using an automated gas-phase sequencer, and molecular mass of this peptide was analyzed using mass spectrometry. In addition, the cross-reactivity of anti-coupling factor 6 $\mathrm{Ab}$ was checked by Western blot analysis using the heart extract. Briefly, the hearts from SHRs were boiled in water for 10 minutes and extracted with $1 \mathrm{M}$ acetic acid. After desalting through a Sep-Pak C18 column, followed by acetone precipitation at a concentration of $66 \%$, the resulting supernatant was evaporated in vacuo until it was dry. The heart extract was subjected to SDSPAGE using a gradient gel. Protein was transferred electrophoretically to a nitrocellulose membrane, treated with anti-coupling factor $6 \mathrm{Ab}$, and stained by amplified alkaline phosphatase immunoblot kits.

Determination of coupling factor 6 gene expression. Total RNA was prepared from the aorta using the Trizol RNA purification system. The cDNA was prepared from mRNA with oligo (dT) primers (30 $\mathrm{ng} / \mu \mathrm{g} \mathrm{RNA})$ using MMLV reverse transcriptase and the conditions recommended by the manufacturer. The cDNA were amplified in $100 \mu \mathrm{l}$ PCR reaction mixture ( $8 \mathrm{mM}$ dNTPs final concentration) containing $2.5 \mathrm{U}$ of Taq polymerase in the buffer supplied by the manufacturer and $0.5 \mu \mathrm{M}$ primers. Oligonucleotide primers designed against the
$\mathrm{N}$-terminal region of coupling factor 6 (31) were forward primer $5^{\prime}$-TGTCCTTCGGTCAGCAGTCTC- $3^{\prime}$ and reverse primer $5^{\prime}$-AACTTATCCATCTCTCCTTTA- $3^{\prime}$. The PCR products were separated on $1.7 \%$ agarose gel containing $0.001 \%$ ethidium bromide and photographed under ultraviolet irradiation at $320 \mathrm{~nm}$. To assess relative quantities of cDNA, a second PCR amplification was conducted with primer directed to the rat housekeeping gene GAPDH, as described previously (32). All PCR procedures were performed as follows: 25 cycles for coupling factor 6 and GAPDH ( 45 seconds at $94^{\circ} \mathrm{C}, 45$ seconds at $52^{\circ} \mathrm{C}$ for coupling factor 6 and 45 seconds at $62^{\circ} \mathrm{C}$ and 1 minute at $72^{\circ} \mathrm{C}$ for GAPDH) and final elongation $\left(5\right.$ minutes at $\left.72^{\circ} \mathrm{C}\right)$.

Immunofluorescence microscopy. CRL-2222 cells were plated at $5 \times 10^{5}$ cells $/ \mathrm{ml}$ on glass coverslips and allowed to adhere overnight in Earle's minimum essential medium containing $10 \% \mathrm{FBS}$. Cells were incubated at $4^{\circ} \mathrm{C}$ for 1 hour in PBS, pH 7.0, containing 1\% BSA with either rabbit polyclonal antiserum raised against the coupling factor 6 of ATP synthase or preimmune rabbit serum. Cells were washed and incubated at $4^{\circ} \mathrm{C}$ for 1 hour in the dark with goat anti-rabbit IgG conjugated to fluorescein isothiocyanate before washing. Immunofluorescence microscopy was performed by using an Olympus BX-60 microscope (Olympus, Tokyo, Japan).

Blood pressure measurement. Blood pressure was determined by direct arterial cannulation in rats anesthetized with $75 \mathrm{mg} / \mathrm{kg}$ of ketamine hydrochloride and $15 \mathrm{mg} / \mathrm{kg}$ of xylazine hydrochloride. Two polyethylene catheters filled with heparinized saline solution (20 U heparin $/ \mathrm{ml}$ ) were inserted via the left carotid artery and left femoral vein, respectively. The carotid catheter was connected to a pressure transducer coupled to a polygraph. Rat recombinant coupling factor 6 , anti-coupling factor 6 $\mathrm{Ab}$, nonspecific anti-rabbit IgG, and bradykinin, in 100 $\mu \mathrm{l}$ saline, were injected and flushed with an additional $200 \mu \mathrm{l}$ saline into the vena cava. The effect of either recombinant coupling factor $6(0.1,0.3$, and $1.0 \mu \mathrm{g} / \mathrm{kg}$ body weight), or anti-coupling factor $6 \mathrm{Ab}(0.3,1.0$, and $3.0 \mu \mathrm{g} / \mathrm{kg}$ body weight), and Fab fraction of the $\mathrm{Ab}(3.0$ $\mu \mathrm{g} / \mathrm{kg}$ body weight) on the arterial vascular tone was examined in SHRs and WKYs at the age of 16 weeks.

The responses of blood pressure to recombinant coupling factor 6 and its Ab were also investigated $30 \mathrm{~min}$ utes after the intravenous injection of indomethacin at $10 \mathrm{mg} / \mathrm{kg}$ in SHRs at the age of 16 weeks. To examine whether endogenous coupling factor 6 influences the hypotensive effect of bradykinin, we further evaluated the blood pressure-lowering effect of bradykinin $(0.3,1.0$, and $3.0 \mu \mathrm{g} / \mathrm{kg}$ body weight) with or without preadministration of anti-coupling factor $6 \mathrm{Ab}$ (3.0 $\mu \mathrm{g} / \mathrm{kg}$ body weight).

Effect of arterial pressure elevation on plasma coupling factor 6 concentration. In WKYs at the age of 16 weeks, norepinephrine was infused at a rate of $5 \mu \mathrm{g} /$ minute in order to increase systemic arterial pressure to $180-200 \mathrm{mmHg}$. After the exposure of the rat to arterial pressure elevation for 30 minutes, arterial blood sampling was performed. 
a

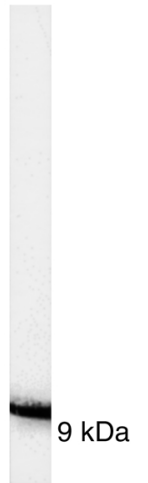

b

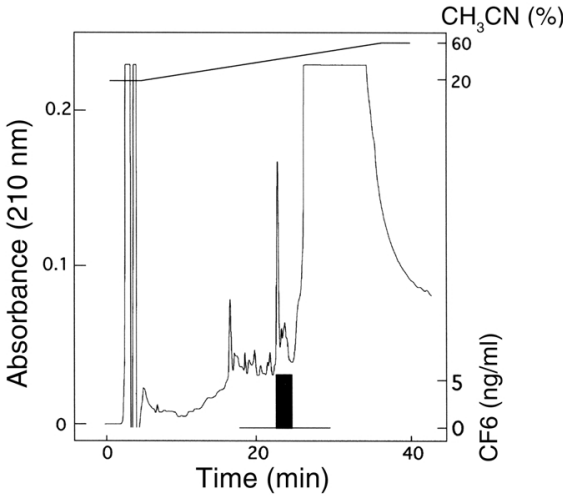

Figure 1

(a) Western blot analysis of coupling factor 6 (CF6) in the heart extract from SHRs. (b) Reverse-phase HPLC of plasma samples monitored by RIA for rat CF6. The filled bar indicates the elution position and concentration of rat CF6.

RIA of 6-keto-PGF $F_{1 \alpha}$. In CRL-2222 cells grown in 12-well plates, the production of prostacyclin was examined in the serum-free medium in the presence of either recombinant coupling factor 6 , a function-perturbing $\mathrm{Ab}$, or an inactive form of recombinant coupling factor 6 , which was prepared by digestion with trypsin $(50: 1 \mathrm{wt} / \mathrm{wt})$ for 6 hours at $37^{\circ} \mathrm{C}$. In addition, the effect of recombinant coupling factor 6 on the production of prostacyclin was investigated in the presence of exogenous AA. The kinetics of plasma prostacyclin accumulation in 16-week-old SHRs was examined by measuring 6-keto-PGF ${ }_{1 \alpha}$ at 0,15 , 30 , and 60 seconds after injecting animals with recombinant coupling factor $6(1.0 \mu \mathrm{g} / \mathrm{kg}$ body weight $)$ or its $\mathrm{Ab}$ $(3.0 \mu \mathrm{g} / \mathrm{kg}$ body weight). 6 -keto-PGF $1 \alpha$ was measured by RIA after partial extraction using a specific $\mathrm{Ab}$ to 6-keto$\mathrm{PGF}_{1 \alpha}$. Briefly, the samples were applied to ODS C18 suspension with $1 \mathrm{~N} \mathrm{HCl}$ and washed with ethanol and petro-ether. After extraction with acetic ether, the elute was fractionated by silica minicolumn, and the concentration of 6-keto-PGF ${ }_{1 \alpha}$ was measured by RIA.

Statistics. All data are shown as mean \pm 1 SE. An unpaired $t$ test for comparison of two variables, one-way ANOVA, ANOVA for repeated measures, and two-way ANOVA for multiple comparisons were used for statistical analysis. The level of significance was less than 0.05 .

\section{Results}

In vitro studies of coupling factor 6 . The effects of recombinant coupling factor 6 and its $A b$ on prostacyclin synthesis were examined in vascular endothelial cells, and the $\mathrm{Ab}$ was characterized in vitro. Prostacyclin synthesis at baseline was $607 \pm 82 \mathrm{pg} /$ well per 24 hours in CRL-2222 cells. Recombinant coupling factor 6 at $10^{-8} \mathrm{M}$ significantly suppressed prostacyclin synthesis to $232 \pm 58$ $\mathrm{pg} /$ well per 24 hours $(P<0.05$ vs. baseline; $n=7)$, whereas it did not affect prostacyclin synthesis in the presence of exogenous AA (1973 \pm 264 in the presence and $2422 \pm 583$ $\mathrm{pg} /$ well per 24 hours in the absence of coupling factor 6 ; $n=4, P=\mathrm{NS}$ ). Inactive recombinant coupling factor 6 treated with trypsin did not show any inhibitory effect on prostacyclin synthesis $(n=4)$. In contrast, anti-coupling factor $6 \mathrm{Ab}$ at $0.14 \mu \mathrm{g} / \mathrm{ml}$ significantly enhanced prostacyclin synthesis to $836 \pm 33 \mathrm{pg} /$ well per 24 hours $(P<0.05$ vs. baseline; $n=7$ ).

Western blot analysis showed that there was a single immunoreactive compound at $9 \mathrm{kDa}$ in the heart extract (Figure 1a). As shown in Figure 1b, one peak of immunoreactive coupling factor 6 emerged from the rat plasma at a position identical to that of authentic rat coupling factor 6 . The amino acid sequence of the immunoreactive fraction, examined by automated gasphase sequencer, was NKELDPVQKLFLDKIREYKA from the $\mathrm{N}$ terminus and was completely identical to that of rat coupling factor 6 . Furthermore, molecular mass of this peptide analyzed by mass spectrometry was 8,925 and was identical to that of rat coupling factor 6 .

Expression of coupling factor 6 in cell culture and tissues. As illustrated in Figure 2, coupling factor $6 \mathrm{mRNA}$ is expressed in the aorta of control 16-week-old WKY rats and at significantly higher levels in age-matched SHRs. The ratio of coupling factor 6 to GAPDH mRNA in the aorta was significantly higher, by 2.5 -fold \pm 0.5 -fold, in SHRs than in WKYs $(P<0.05, n=3)$.

To determine whether endothelial cells might represent a source of circulating coupling factor 6 , we turned to CRL-2222 rat vascular endothelial cells to study the expression of coupling factor 6 on the cell surface and the rate at which it is released in culture. Immunofluorescence microscopy of CRL-2222 cells confirmed the surface-associated immunoreactivity of anti-coupling factor $6 \mathrm{Ab}$ on cell membranes (Figure $3 \mathrm{a}$ ). The same field of CRL-2222 cells under visible light is shown in Figure $3 \mathrm{~b}$. Control experiments were performed with preimmune serum alone (Figure $3 \mathrm{c}$ ) and secondary $\mathrm{Ab}$ alone (Figure 3d). The immunofluorescence was completely inhibited with recombinant coupling factor 6 .

Conditioned medium from confluent CRL-2222 cells accumulated coupling factor 6 to levels of $19.8 \pm 3.1$ $\mathrm{ng} /$ dish at 24 hours, $50.8 \pm 5.4 \mathrm{ng} / \mathrm{dish}$ at 48 hours, and $63.4 \pm 8.6 \mathrm{ng} / \mathrm{dish}$ at 72 hours. In proportion to the increase in coupling factor 6 , the production rate of prostacyclin decreased from $525 \pm 25 \mathrm{pg} /$ day at 24 hours to $206 \pm 33 \mathrm{pg} /$ day at 48 hours and $106 \pm 66$ $\mathrm{pg} /$ day at 72 hours $(n=4)$. Trypan blue-positive cells were undetectable under these conditions.

Expression of coupling factor 6 in vivo. The plasma concentrations of coupling factor 6 in the rats showing nor-
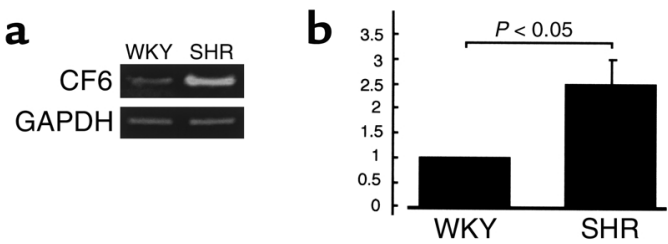

\section{Figure 2}

The gene expression of coupling factor 6 (CF6) in the aorta from WKYs and SHRs. (a) Representative bands of CF6 and GAPDH. (b) The ratio of CF6 to GAPDH mRNA in WKYs and SHRs $(n=3)$. 


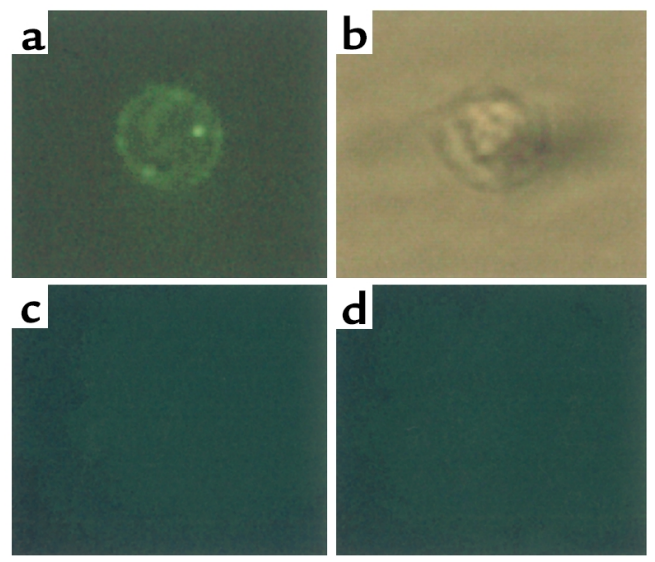

Figure 3

Immunofluorescence microscopy of coupling factor 6 (CF6) in ATP synthase on CRL-2222 cell surfaces. (a) CRL-2222 cells under epiillumination showing immunofluorescent surface staining for the CF6 of ATP synthase. (b) The same field of CRL-2222 cells under visible light. (c) Incubation with preimmune serum alone. (d) Incubation with secondary $\mathrm{Ab}$ alone.

mal and high blood pressures appear to vary with age and with genetic background. The plasma concentration of rat coupling factor 6 were $414 \pm 123 \mathrm{pg} / \mathrm{ml}$ and $294 \pm 126 \mathrm{pg} / \mathrm{ml}$ in WKYs at the ages of 4 and 16 weeks, respectively. In SHRs, the concentration at the age of 4 weeks (prehypertensive stage) was $216 \pm 108 \mathrm{pg} / \mathrm{ml}$ and did not differ from that in WKYs, whereas at the age of 16 weeks (hypertensive stage) it was $2,310 \pm 813 \mathrm{pg} / \mathrm{ml}$ and significantly greater than those in normotensive WKYs and prehypertensive SHRs (both $P<0.05$ ).

In WKYs at the age of 16 weeks, the plasma concentration of coupling factor 6 was unchanged after 30-minute continuous elevation of arterial blood pressure by the intravenous injection of norepinephrine $(216 \pm 39 \mathrm{pg} / \mathrm{ml}$ vs. $159 \pm 15 \mathrm{pg} / \mathrm{ml} ; P=\mathrm{ns}, n=4)$.

Physiological effects of perturbing coupling factor 6 activity in vivo. To assess the role of coupling factor 6 in vivo, we determined the prostacyclin levels in the plasma after injection of recombinant coupling factor 6 or its $\mathrm{Ab}$ in SHRs. After intravenous bolus injection of recombinant coupling factor 6 at $1.0 \mu \mathrm{g} / \mathrm{kg}$, the plasma concentration of 6-keto-PGF $\mathrm{PG}_{1 \alpha}$ decreased significantly by $38.7 \% \pm 7.7 \%$ at 15 seconds $(P<0.05), 36.4 \% \pm 11.2 \%$ at 30 seconds $(P<0.05)$, and $18.2 \% \pm 0.3 \%$ at 60 seconds from the baseline $(n=4)$ (Figure 4$)$. In contrast, 6-ketoPGF $_{1 \alpha}$ levels increased by $38.7 \% \pm 8.3 \%$ at 15 seconds, by $41.6 \% \pm 6.0 \%$ at 30 seconds, and by $28.8 \% \pm 8.0 \%$ at 60 seconds after intravenous bolus injection of anti-coupling factor $6 \mathrm{Ab}$ at $3.0 \mu \mathrm{g} / \mathrm{kg}($ all $P<0.05 ; n=4)$.

To clarify whether the effect of endogenous coupling factor 6 is dependent on prostacyclin, we investigated the effect of pretreatment with indomethacin, an inhibitor of cyclooxygenase operating downstream of $\mathrm{PLA}_{2}$. The injection of indomethacin alone increased systolic blood pressure by $10 \pm 3 \mathrm{mmHg}$. Figure 5 a illustrates representative tracings of changes in arterial blood pressure after an injection of anti-coupling factor $6 \mathrm{Ab}$ into the femoral vein. In 16-week-old WKYs, the intravenous bolus injection of anti-coupling factor $6 \mathrm{Ab}$ at $0.3,1.0$, and $3.0 \mu \mathrm{g} / \mathrm{kg}$ body weight produced a transient and rapid reduction in systolic and diastolic blood pressures. In age-matched SHRs, the reduction of blood pressure occurred in seconds, reached a maximal reduction within 30 seconds, and returned to the baseline after several minutes. It was noted that the reduction of blood pressure was greater in SHRs than in WKYs. The reduction of blood pressure was blocked after 30 -minute pretreatment with indomethacin at $10 \mathrm{mg} / \mathrm{kg}(n=3)$.

Figure $5 \mathrm{~b}$ shows the dose-dependent effect of anti-coupling factor $6 \mathrm{Ab}$ on mean blood pressure. In 16-week-old WKYs, the reduction of mean blood pressure after administration of more than $0.3 \mu \mathrm{g} / \mathrm{kg}$ of Ab was significant and dose dependent $(-7 \pm 2 \mathrm{mmHg}$ at $0.3,-8 \pm 3 \mathrm{mmHg}$ at 1 , and $-10 \pm 2 \mathrm{mmHg}$ at $3 \mu \mathrm{g} / \mathrm{kg}$ ). In age-matched SHRs, it also was significant and dose dependent $(-16 \pm 4 \mathrm{mmHg}$ at $0.3,-19 \pm 2 \mathrm{mmHg}$ at 1 , and $-30 \pm 4 \mathrm{mmHg}$ at $3 \mu \mathrm{g} / \mathrm{kg}$ ), and the changes were significantly greater than those in WKYs $(P<0.01$ by twoway ANOVA). Intravenous bolus injection of Fab fraction of the $\mathrm{Ab}(3 \mu \mathrm{g} / \mathrm{kg})$ induced a reduction of mean blood pressure similar to the effect of anti-coupling factor $6 \mathrm{Ab}$ in both strains, and the reduction was greater in SHRs than in WKYs $(-28 \pm 4 \mathrm{mmHg}$ vs. $-9 \pm 2 \mathrm{mmHg}$; $P<0.05)$. Injection of nonspecific anti-rabbit IgG had no effect on arterial blood pressure even at a dose threefold $(10 \mu \mathrm{g} / \mathrm{kg})$ more than the anti-coupling factor $6 \mathrm{Ab}$.

In a 16-week-old WKY, an intravenous bolus injection of rat recombinant coupling factor 6 at $1.0 \mu \mathrm{g} / \mathrm{kg}$ body weight produced a transient and rapid increase in systolic and diastolic arterial blood pressures (Figure 6a). In an age-matched SHR, the peptide increased arterial blood pressure more markedly within seconds, reaching the maximal increase within 30 seconds and returning to baseline after several minutes. Injection of coupling factor 6 following a 30-minute pretreatment with indomethacin at $10 \mathrm{mg} / \mathrm{kg}$ had no additional effect on blood pressure beyond that produced by the drug alone $(n=3)$. Figure $6 \mathrm{~b}$ shows the dose dependence of the effect of recombinant coupling factor 6 on mean blood pressure. At doses of more than $0.3 \mu \mathrm{g} / \mathrm{kg}$, coupling

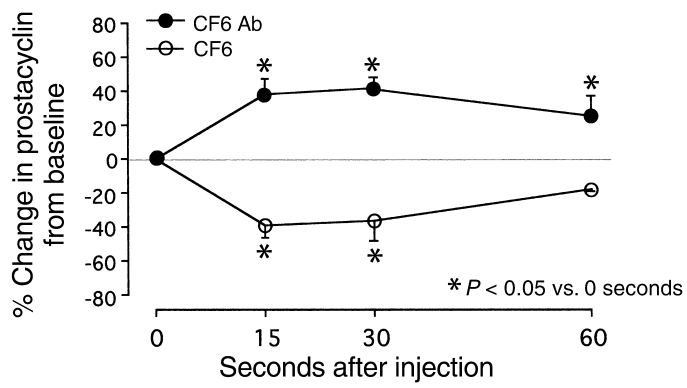

\section{Figure 4}

Kinetics of prostacyclin in the plasma after intravenous bolus injection of rat recombinant coupling factor 6 (CF6) at $1 \mu \mathrm{g} / \mathrm{kg}(n=4)$ and anti-coupling factor $6 \mathrm{Ab}(\mathrm{CF} 6 \mathrm{Ab})$ at $3 \mu \mathrm{g} / \mathrm{kg}(n=4)$ in SHRs at the age of 16 weeks. 
a

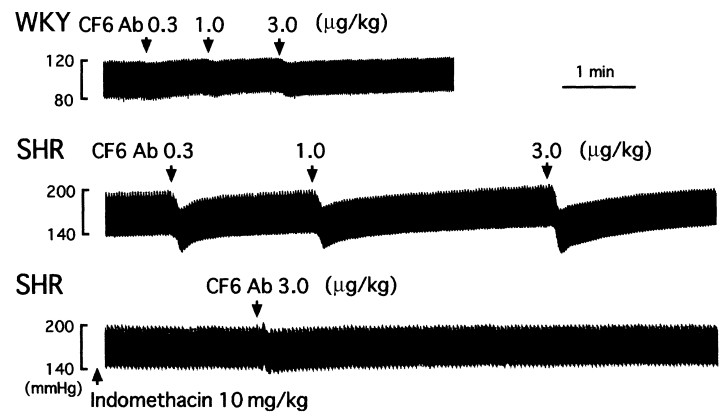

b

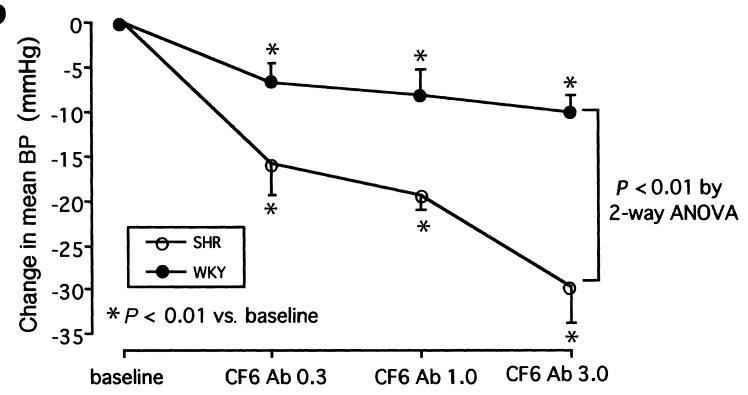

Figure 5

(a) Changes in the arterial blood pressure after intravenous injection of anti-coupling factor $6 \mathrm{Ab}$ (CF6 Ab) in WKYs and SHRs at the age of 16 weeks. It is noted that pretreatment with indomethacin at $10 \mathrm{mg} / \mathrm{kg}$ for 30 minutes blocked the decrease in blood pressure after injection of CF6 Ab in SHRs. (b) Dose-response effects of anti-coupling factor 6 Ab on mean arterial blood pressure (BP) in WKYs $(n=7)$ and SHRs $(n=7)$ at the age of 16 weeks. Statistical analysis was performed by ANOVA for repeated measures and two-way ANOVA.

factor 6 caused a significant and dose-dependent increase in mean blood pressure $(0.7 \pm 0.3 \mathrm{mmHg}$ at $0.1,1.3 \pm 0.7 \mathrm{mmHg}$ at 0.3 , and $4.5 \pm 0.6 \mathrm{mmHg}$ at 1.0 $\mu \mathrm{g} / \mathrm{kg}$ body weight) in WKYs. This increase was also significant and dose-dependent $(2.5 \pm 0.5 \mathrm{mmHg}$ at 0.1 , $6.0 \pm 1.0 \mathrm{mmHg}$ at 0.3 , and $12.0 \pm 1.3 \mathrm{mmHg}$ at 1.0 $\mu \mathrm{g} / \mathrm{kg}$ body weight) in SHRs. The increase in mean blood pressure in SHRs was significantly greater than that in WKYs $(P<0.01$ by two-way ANOVA).

Effects of bradykinin. Recombinant coupling factor 6 inhibits bradykinin-induced prostacyclin production in vitro (9). We therefore examined the effect of pretreatment with anti-coupling factor $6 \mathrm{Ab}$ on bradykinininduced hypotension. Figure 7a illustrates representative tracings of arterial blood pressure change after injections of bradykinin with or without pretreatment with anti-coupling factor $6 \mathrm{Ab}$. Intravenous bolus injections of bradykinin (0.3-3 $\mu \mathrm{g} / \mathrm{kg}$ body weight) induced a transient and rapid reduction of systolic and diastolic blood pressures. Pretreatment with anti-coupling factor $6 \mathrm{Ab}$ at $3 \mu \mathrm{g} / \mathrm{kg}$ did not affect bradykinin-induced reduction of blood pressure in 16-week-old WKYs. In contrast, the blood pressure-lowering effect of bradykinin was enhanced by pretreatment with anti-coupling factor 6 $\mathrm{Ab}$ in SHRs. As shown in Figure 7b, the decrease in mean blood pressure was significant and dose dependent at doses of $>0.3 \mu \mathrm{g} / \mathrm{kg}$ bradykinin. In WKYs, the decrease was unaffected by anti-coupling factor $6 \mathrm{Ab}$. The hypotensive effect of bradykinin was significantly enhanced after pretreatment with anti-coupling factor $6 \mathrm{Ab}$ in SHRs $(-4 \pm 1$ vs. $-11 \pm 1 \mathrm{mmHg}$ at $0.3 \mu \mathrm{g} / \mathrm{kg}$ bradykinin and $-20 \pm 2$ vs. $-25 \pm 2 \mathrm{mmHg}$ at $3 \mu \mathrm{g} / \mathrm{kg}$ bradykinin; $P<0.05$ by two-way ANOVA). In SHRs, pretreatment with $3 \mu \mathrm{g} / \mathrm{kg}$ of $\mathrm{Fab}$ fraction of anti-coupling factor $6 \mathrm{Ab}$ also enhanced the decrease in mean blood pressure seen upon treatment with bradykinin at 3 $\mu \mathrm{g} / \mathrm{kg}(-20 \pm 2$ vs. $-27 \pm 2 \mathrm{mmHg} ; P<0.05)$.

\section{Discussion}

Coupling factor 6 , a component of the mitochondrial ATP synthase, is known to be essential for energy transduction. Here, we demonstrated that this peptide is an endogenous inhibitor for prostacyclin synthesis in the rat vascular endothelial cells. We hypothesized that mitochondrial coupling factor 6 is shed into the circulation where it leads to elevated blood pressure. The results clearly showed that coupling factor 6 was present on the surface of vascular endothelial cells and in the systemic circulation, that its concentration was significantly elevated at the hypertensive stage, and that coupling factor
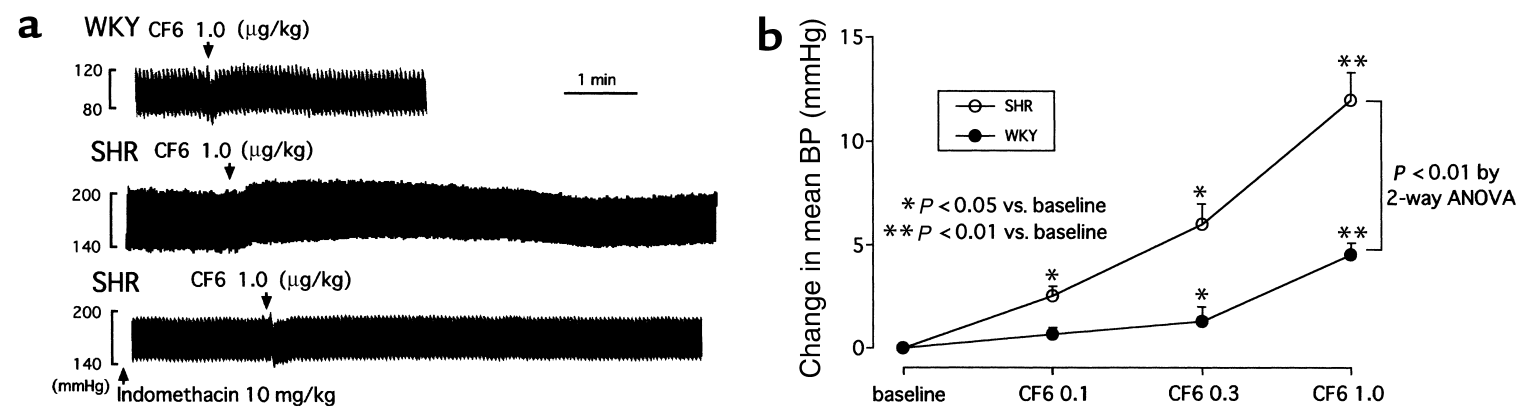

Figure 6

(a) Changes in the arterial blood pressure after intravenous injection of rat recombinant coupling factor 6 (CF6) at $1 \mu \mathrm{g} / \mathrm{kg}$ in WKYs and SHRs at the age of 16 weeks. It is noted that pretreatment with indomethacin at $10 \mathrm{mg} / \mathrm{kg}$ for 30 minutes blocked the increase in blood pressure after injection of CF6 in SHRs. (b) Dose-response effects of rat recombinant coupling factor 6 on mean blood pressure (BP) in WKYs $(n=7)$ and SHRs $(n=7)$ at the age of 16 weeks. Statistical analysis was performed by ANOVA for repeated measures and two-way ANOVA. 

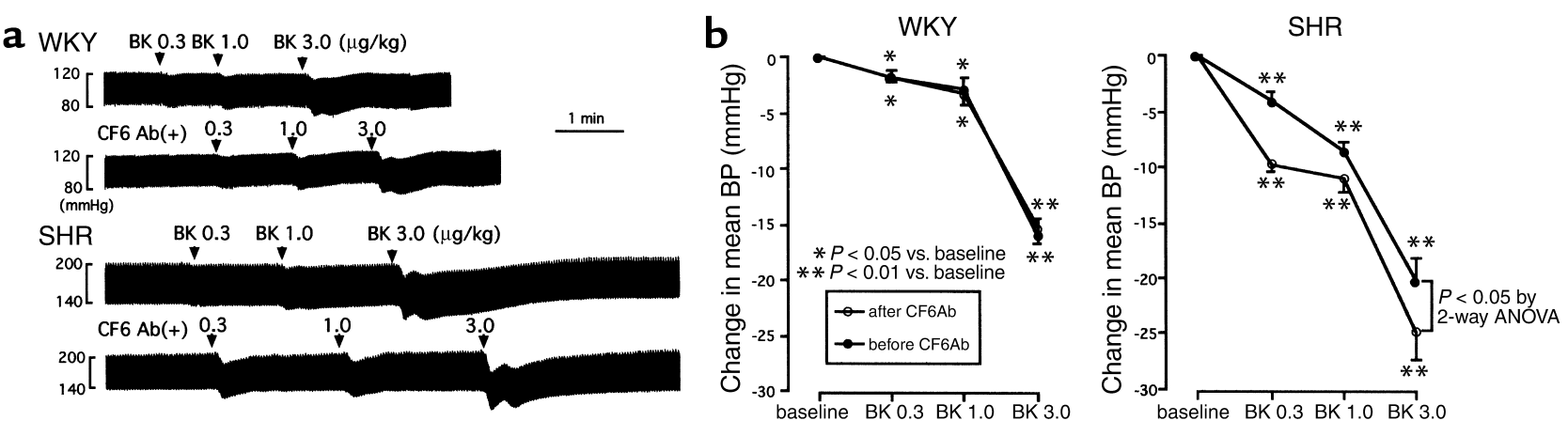

Figure 7

(a) Changes in the arterial blood pressure after intravenous injection of bradykinin (BK) with or without preadministration of anti-coupling factor $6 \mathrm{Ab}(\mathrm{CF} 6 \mathrm{Ab})$ at $3 \mu \mathrm{g} / \mathrm{kg}$ in WKYs and SHRs at the age of 16 weeks. CF6 Ab(+) is the condition in which arterial blood pressure returned to the baseline after preadministration of anti-coupling factor $6 \mathrm{Ab}$ at $3 \mu \mathrm{g} / \mathrm{kg}$. (b) Effects of preadministration of anti-coupling factor $6 \mathrm{Ab}(\mathrm{CF} 6 \mathrm{Ab})$ at $3 \mu \mathrm{g} / \mathrm{kg}$ on the dose-dependent blood pressure-lowering effect of bradykinin in WKYs $(n=7)$ and SHRs $(n=7)$ at the age of 16 weeks. Statistical analysis was performed by ANOVA for repeated measures and two-way ANOVA.

6 is involved in the regulation of arterial blood pressure in physiological and pathological conditions.

Evidence for the presence of circulating coupling factor 6 . Based on the efficiency of extraction and the characterization of immunoreactive coupling factor 6 in the rat plasma, we confirmed that the present RIA system accurately measures plasma concentrations of coupling factor 6 . Coupling factor 6 was detectable in the plasma in both strains of rats at the ages of 4 and 16 weeks, suggesting that this peptide can function as an endogenous prostacyclin-inhibitory substance in vivo. Recently, other components of ATP synthase, such as $\alpha$ and $\beta$ subunits (22), have been found on the vascular endothelial surface. Furthermore, the addition of ATP synthase to cultures of tumor cell lines is known to induce membrane depolarization, changes in permeability, and eventual lysis of a variety of transformed cells (23-29), suggesting that all components of ATP synthase, including coupling factor 6 , must be present on the plasma membrane, as verified here by immunofluorescence. The coupling factor 6 that we have observed in the plasma did not necessarily derive from the vascular endothelial cells, but our evidence that cultured endothelial cells release coupling factor 6 into their medium indicate that the endothelium could be an important source of the circulating peptide.

The plasma concentration of coupling factor 6 was significantly higher in SHRs at the hypertensive stage than in normotensive WKYs and prehypertensive SHRs. Because norepinephrine-induced increase in blood pressure was not accompanied by an increase in the peptide, the higher level of coupling factor 6 in SHRs may be related to the genesis of hypertension and not secondary to hypertension. Since coupling factor 6 expression is proportional to the strength of shear stress in vascular endothelial cells (33), hypertension may be involved in the increase in cell surface coupling factor 6 and the elevation of plasma coupling factor 6 . Coupling factor 6 is synthesized in an immature form in the cytosol but is imported into and accumulates within the mito- chondria (34), suggesting that tissue injury or apoptosis could enhance its release into the systemic circulation. Indeed, apoptosis is reported to be enhanced in the SHR-derived aorta and left ventricle $(35,36)$. Hypertension-induced increase in the mass of the heart, where the peptide is highly expressed $(9,37)$, may also contribute to its elevated levels in plasma from SHRs.

Effects of circulating coupling factor 6 on blood pressure. Like other vasoactive substances, the plasma level of coupling factor $6\left(10^{-10} \mathrm{M}\right)$ was lower than the critical concentration $\left(10^{-8} \mathrm{M}\right)$ at which prostacyclin production in the cultured vascular endothelial cells can be suppressed in vitro (9). We therefore evaluated whether endogenous coupling factor 6 affects arterial blood pressure in vivo by blocking the effect of endogenous coupling factor 6 with anti-coupling factor $6 \mathrm{Ab}$. The results clearly showed that intravenous administration of anti-coupling factor $6 \mathrm{Ab}$ caused a transient and rapid reduction in arterial blood pressure. Furthermore, this blood pressure-lowering effect was related to the plasma levels of the peptide. Thus, in SHRs, where the plasma level was high, the effect of the $\mathrm{Ab}$ was correspondingly great. It should be noted that although the Ab did not crossreact with contaminating rat plasma components, there is still a possibility that the $\mathrm{Ab}$ reacted with other substances when it was injected in vivo. Thus, the in vivo effect of this Ab may not be solely through the inhibition of circulating coupling factor 6 .

In addition to our work with the blocking antibody, we performed complementary studies by treating rats with exogenous recombinant coupling factor 6 . Injected peptide induced an increase in arterial blood pressure, and its extent was similar to that expected from the finding of neutralization of coupling factor 6 , suggesting that its vasoconstrictor effect is unaffected by a single pass through the pulmonary vascular bed. In addition, the concentration of recombinant coupling factor 6 infused into the rat femoral vein was $10^{-10}$ to $10^{-9} \mathrm{M}$ and was within the normal physiological range for this peptide. Taken together, these findings strongly suggest that 
endogenous coupling factor 6 has a direct vasoconstrictor effect in the fashion of a circulating hormone.

Bradykinin, one of several endogenous vasodilators, activates phospholipases $A_{2}$ and $C$ via the $G$ protein-coupled endothelial $\mathrm{B}_{2}$ receptor and stimulates the formation of the potent vasodilators, prostacyclin and nitric oxide $(12,13)$. Because recombinant coupling factor 6 inhibits bradykinin-induced prostacyclin production in vitro (9), we investigated the effect of pretreatment with anti-coupling factor $6 \mathrm{Ab}$ on the blood pressure-lowering effect of bradykinin. The blood pressure-lowering effect of bradykinin was unaffected by this pretreatment in control WKYs. Bradykinin-induced reduction in blood pressure may not be mediated by prostacyclin in a physiological condition. In contrast, the effect of bradykinin was enhanced after treatment with anti-coupling factor $6 \mathrm{Ab}$ in SHRs. This suggests that coupling factor 6 functions by counteracting the effect of bradykinin in hypertension.

In conclusion, this report shows that mitochondrial coupling factor 6 is a potent endogenous vasoconstrictor. In light of the current findings, it appears that mitochondrial coupling factor 6 plays an important and direct role in the regulation of systemic blood pressure in a physiological condition. These data raise the possibility of a new mechanism for the development of hypertension. Because a major acting site of coupling factor 6 is in the inhibition of AA release from the plasma membrane (9), this peptide may influence arterial blood pressure by mechanisms other than prostacyclin inhibition, perhaps by abrogating the AA-induced inhibition of voltage-gated $\mathrm{Ca}^{2+}$ current. Given the widespread biological actions of prostacyclin, the physiological and pathological functions of coupling factor 6 may be expected to be complex.

1. Boyer, P.D. 1993. The binding change mechanism for ATP synthase: some probabilities and possibilities. Biochim. Biophys. Acta. 1140:215-250.

2. Walker, J.E., et al. 1985. Primary structure and subunit stoichiometry of $\mathrm{F}_{1}$-ATPase from bovine mitochondria. J. Mol. Biol. 184:677-701.

3. Kagawa, Y., and Racker, E. 1966. Partial resolution of the enzymes catalyzing oxidative phosphorylation. Correlation of morphology and function in submitochondrial particles. J. Biol. Chem. 241:2475-2482.

4. Walker, J.E., Runswick, M.J., and Poulter, L. 1987. ATP synthase from bovine mitochondria: characterization and sequence analysis of two membrane associated subunits and of their corresponding c-DNAs. J. Mol. Biol. 197:89-100.

5. Collinson, I.R., et al. 1994. ATP synthase from bovine heart mitochondria In vitro assembly of a stalk complex in the presence of $F_{1}$-ATPase and its absence. J. Mol. Biol. 242:408-421.

6. Knowles, A.F., Guillory, R.J., and Racker, E. 1971. Partial resolution of the enzymes catalyzing oxidative phosphorylation XXIV. A factor required for the binding of mitochondrial adenosine triphosphatase to the inner mitochondrial membrane. J. Biol. Chem. 246:2672-2679.

7. Falardeau, P., Robillard, M., and Martineau, A. 1985. Urinary levels of 2,3 dinor-6-oxo-PGF $1 \alpha$ : a reliable index of the production of $\mathrm{PGI}_{2}$ in the spontaneously hypertensive rat. Prostaglandins. 29:621-628.

8. Osanai, T., et al. 1990. Changes in vascular wall production of prostacyclin and thromboxane $\mathrm{A}_{2}$ in spontaneously hypertensive rats during maturation and concomitant development of hypertension. Jpn. Circ. J. 54:507-514.

9. Osanai, T., et al. 1998. A nonel inhibitory effect on prostacyclin synthesis of coupling factor 6 extracted from the heart of spontaneously hypertensive rats. J. Biol. Chem. 273:31778-31783.

10. Murata, T., et al. 1997. Altered pain perception and inflammatory response in mice lacking prostacyclin receptor. Nature. 388:678-682.

11. Nakagawa, O., et al. 1995. Molecular cloning of human prostacyclin recep- tor cDNA and its gene expression in the cardiovascular system. Circulation. 90:1643-1647.

12. Menke, J.G., et al. 1994. Expression cloning of a human B1 bradykinin receptor. J. Biol. Chem. 269:21583-21586.

13. McEachern, A.E., et al. 1991. Expression cloning of a rat $B_{2}$ bradykinin receptor. Proc. Natl. Acad. Sci. USA. 88:7724-7728.

14. Byron, K.L. 1996. Vasopressin stimulates $\mathrm{Ca}^{2+}$ spiking activity in $\mathrm{A} 7 \mathrm{r} 5$ vascular smooth muscle cells via activation of phospholipase $\mathrm{A}_{2}$. Circ. Res. 78:813-820.

15. Dennis, E.A. 1994. Diversity of group types, regulation, and function of phospholipase $\mathrm{A}_{2}$.J. Biol. Chem. 269:13057-13060.

16. Murakami, M., Kudo, I., and Inoue, K. 1993. Molecular nature of phospholipase $\mathrm{A}_{2}$ involved in prostaglandin $\mathrm{I}_{2}$ synthesis in human umbilical vein endothelial cells. J. Biol. Chem. 268:839-844.

17. Yamauchi, T., et al. 1994. Purification and molecular cloning of prostacyclin-stimulating factor from serum-free conditioned medium of human diploid fibroblast cells. Biochem. J. 303:591-598.

18. Kanai, N., et al. 1995. Identification and characterization of a prostaglandin transporter. Science. 268:866-869.

19. Flower, R.J., and Blackwell, G.J. 1979. Anti-inflammatory steroids induce biosynthesis of a phospholipase $\mathrm{A}_{2}$ inhibitor which prevents prostaglandin generation. Nature. 278:456-459.

20. Blackwell, G.J., et al. 1980. Macrocortin: a polypeptide causing the antiphospholipase effect of glucocorticoids. Nature. 287:147-149.

21. Hirata, F., et al. 1981. Presence of autoantibody for phospholipase inhibitory protein, lipomodulin, in patients with rheumatic diseases. Proc. Natl. Acad. Sci. USA. 78:3190-3194.

22. Moser, T.L., et al. 1999. Angiostatin binds ATP synthase on the surface of human endothelial cells. Proc. Natl. Acad. Sci. USA. 96:2811-2816.

23. Virgilio, F.D., Pizzo, P., Zanovello, P., Bronte, V., and Collavo, D. 1990 Extracellular ATP as a possible mediator of cell-mediated cytotoxicity. Immunol. Today. 11:274-277.

24. Rozengurt, E., Heppel, L.A., and Friedberg, I. 1977. Effect of exogenous ATP on the permeability properties of transformed cultures of mouse cell lines. J. Biol. Chem. 252:4584-4590.

25. Rozengurt, E., and Heppel, L.A. 1979. Reciprocal control of membrane permeability of transformed cultures of mouse cell lines by external and internal ATP. J. Biol. Chem. 254:708-714.

26. Chahwala, S.B., and Cantley, L.C. 1984. Extracellular ATP induces ion fluxes and inhibits growth of Friend erythroleukemia cells. J. Biol. Chem. 259:13717-13722

27. Saribas, A.S., Lustig, K.D., Zhang, X., and Weisman, G.A. 1993. Extracellular ATP reversibly increases the plasma membrane permeability of transformed mouse fibroblasts to large macromolecules. Anal. Biochem. 209:45-52.

28. Virgilio, D.F., Bronte, V., Collava, D., and Zanovello, P. 1989. Responses of mouse lymphocytes to extracellular adenosine $5^{\prime}$-triphosphate (ATP). Lymphocytes with cytotoxic activity are resistant to the permeabilizing effects of ATP. J. Immunol. 143:1955-1960.

29. Zanovello, P., Bronte, V., Rosato, A., Pizzo, P., and Virgilio, D.F. 1990 Responses of mouse lymphocytes to extracellular ATP. II. Extracellular ATP causes cell type-dependent lysis and DNA fragmentation. Immunol. 145:1545-1550.

30. Yabuta, Y., Suzuki, Y., and Ohsuye, K. 1995. High expression of a recombinant human calcitonin precursor peptide in Escherichia coli. Appl. Microbiol. Biotechnol. 42:703-708.

31. Higuti, T., et al. 1991. Molecular cloning of cDNA for the import precursor of human coupling factor 6 of $\mathrm{H}^{+}$-ATP synthase in mitochondria. Biochem. Biophys. Res. Commun. 178:793-799.

32. Verde, I., Vandecasteele, G., Lezoualc'h, F., and Fischmeister, R. 1999. Characterization of the cyclic nucleotide phospodiesterase subtypes involved in the regulation of the $\mathrm{L}$-type $\mathrm{Ca}^{2+}$ current in rat ventricular myocytes. $\mathrm{Br}$. J. Pharmacol. 127:65-74.

33. Ando, J., et al. 1996. Differential display and cloning of shear stress-responsive messenger RNAs in human endothelial cells. Biochem. Biophys. Res. Commun. 225:347-351.

34. Higuti, T., et al. 1991. Molecular cloning of cDNA for the import precursor of human coupling factor 6 of $\mathrm{H}^{+}$-ATP synthase in mitochondria. Biochem. Biophys. Res. Commun. 178:793-799.

35. Sharifi, A.M., and Schiffrin, E.L. 1998. Apoptosis in vasculature of spontaneously hypertensive rats: effect of an angiotensin converting enzyme inhibitor and a calcium channel antagonist. Am. J. Hypertens. 11:1108-1116.

36. Fortuno, M.A., Ravassa, S., Etayo, J.C., and Diez, J. 1998. Overexpression of Bax protein and enhanced apoptosis in the left ventricle of spontaneously hypertensive rats: effects of AT1 blockade with losartan. Hypertension. 32:280-286.

37. Sangawa, H., Himeda, T., Shibata, H., and Higuti, T. 1997. Gene expression of subunit c (P1), subunit c (P2), and oligomycin sensitivity-conferring protein may play a key role in biogenesis of $\mathrm{H}^{+}$-ATP synthase in various rat tissues. J. Biol. Chem. 272:6034-6037. 